\title{
Impacted Metallic Foreign Body in the Face
}

\author{
Vimala G, Bagadeesh Palanisamy*, Kannan Ross
}

Institute of general surgery, Madras medical college\& Rajiv Gandhi Government General Hospital, Chennai, Tamilnadu, India

DOI: $10.36347 /$ sasjs.2020.v06i02.004

| Received: 01.02.2020 | Accepted: 08.02.2020 | Published: 12.02.2020

*Corresponding author: Dr. Bagadeesh Palanisamy

\section{Abstract}

Foreign body lodged in soft tissue is common in road traffic accidents and industrial accidents. The purpose of reporting this case is to highlight that usually the foreign body is present at the site of entry but in this case it travels a short distance and get impacted in another area, which was diagnosed with the help of clinical examination and radiological investigations and that region was explored and foreign body was removed.

Keywords: Metallic, foreign body, CT scan.

Copyright @ 2020: This is an open-access article distributed under the terms of the Creative Commons Attribution license which permits unrestricted use, distribution, and reproduction in any medium for non-commercial use (NonCommercial, or CC-BY-NC) provided the original author and source are credited.

\section{INTRODUCTION}

Facial and neck injuries have high risk of morbidity and mortality due to factors like massive blood loss from the carotid arteries and jugular veins and upper airway obstruction which can be due to edema, hematoma or emphysema that might compress the airway. Early wound exploration and proper wound debridement with adequate antimicrobial coverage are the prime factors deciding the morbidity and mortality. Irrespective of the problem the overall mortality is relatively low from $0 \%$ to $11 \%$. Penetrating injures caused by sharp metallic objects are a major proportion of all laceration observed in emergency departments. Once embedded in soft tissue metallic fragments are difficult to detect and retrieve if it is small and multiple. Identification of the foreign body in the face is difficult with clinical evaluation and routine radiographs. Use of diagnostic tools like ultrasonography, CT scan and MRI are better modalities.

\section{CASE REPORT}

22 years old male patient a metal fitter by occupation had been hammering on a piece of metal that shattered on impact presented with complaints of wound in the left lateral aspect of the neck. History of mild bleeding from the wound and pain in the entry site and also in the pre tragus area was present. On examination $2 * 2 * 1 \mathrm{~cm}$ laceration was present and there was no active bleeding, wound exploration and wash was given under local anaesthesia and there was no foreign body at the site of entry. There was a hard palpable well defined fixed swelling with tenderness was present in the pre tragus area on the left side.

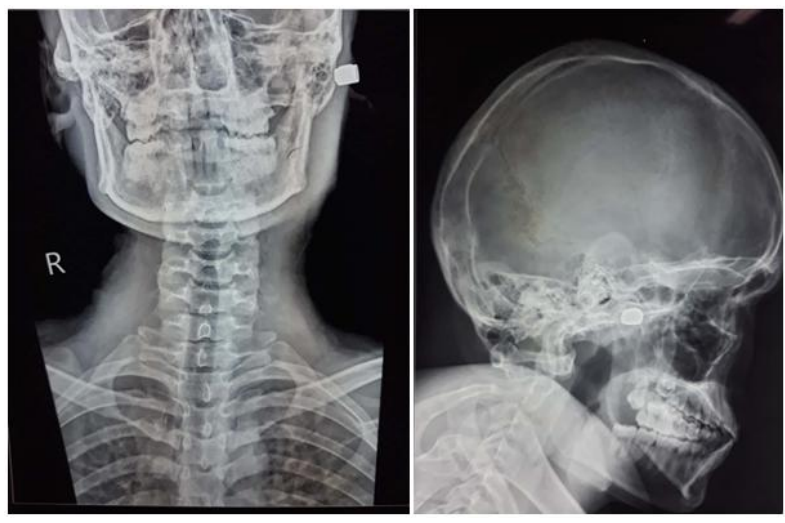

Fig-1: Plain radiography picture showing hyperdense foreign body over left zygoma bone

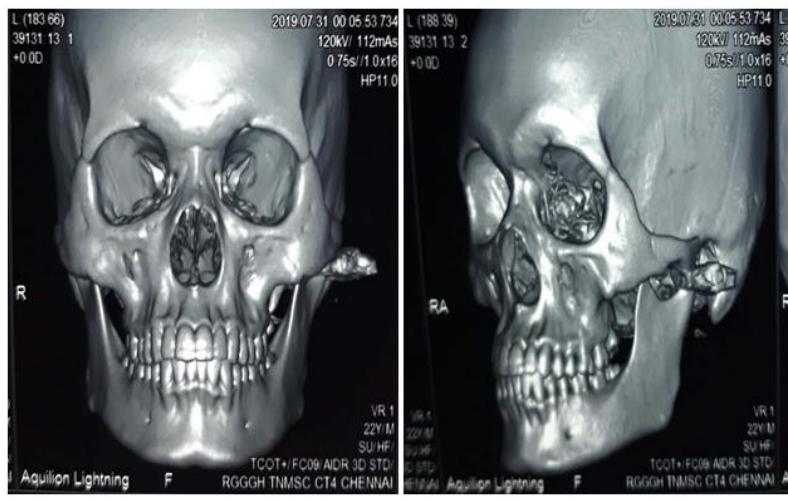

Fig-2: CT facial bone showing metallic foreign body over left zygoma bone just anterior to external auditory meatus 


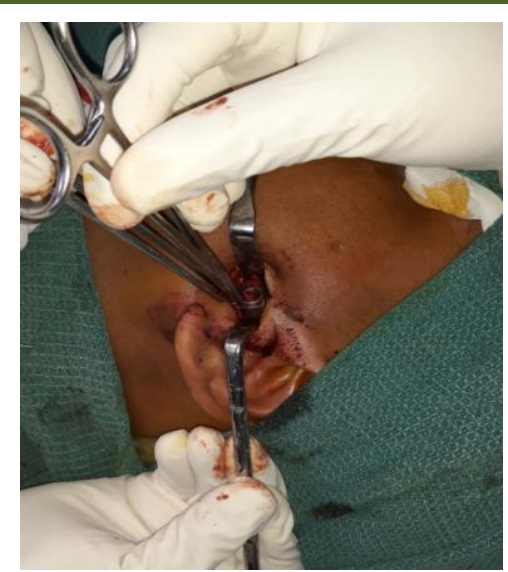

Fig-3: Operative picture showing metallic foreign body during removal

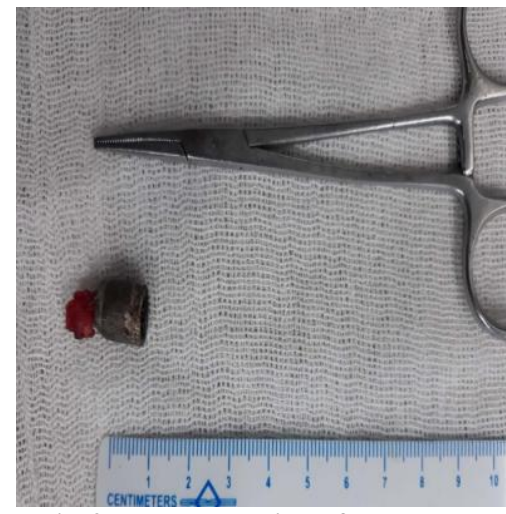

Fig-4: The metal object after removal

Radiological investigations like $\mathrm{X}$ ray and $\mathrm{CT}$ scan was done which showed $1 * 1 \mathrm{~cm}$ bullet like hyperdense foreign body in the left pre tragus area over zygomatic arch. Patient was diagnosed as having metallic foreign body in the face which entered in the lateral aspect of the neck and travel a short distance gets impacted in the pre tragus area over the zygomatic arch. Foreign body retrieval was planned under general anaesthesia and incision was made over the swelling, the metal piece was found deep to the muscle and adherent to the surrounding structures which was removed and wound closed in layers. No complications in the post operative period.

\section{DISCUSSION}

Foreign bodies are often encountered by surgeons in emergency department and may present a diagnostic challenge due to many factors like size of the object, the difficult access and the close anatomical relationship of the foreign body to vital structures. The foreign bodies can penetrate soft tissues through open wounds and lacerations sustained during trauma or by direct impact against them. Such wounds may be smaller and also have no major symptoms but have foreign body, if that is left untreated can lead to medical and surgical problems even after the long time. Computed tomography is the investigation of choice to detect foreign body in the majority of cases, about one third of the cases are missed or misdiagnosed in the initial period. There is usually difficulty in removing the foreign body because they are close to vital structures and also the difficult access. The careful assessment is required to identify the foreign body and locate them, which is essential for surgical removal. Ultrasound is both sensitive and specific in detecting wooden foreign body. Proper wound care, intravenous antibiotics and analgesics promotes wound healing better after foreign body removal.

\section{CONCLUSION}

In this case the metallic foreign body entry and the impacted site are different, so entry wound exploration along with radiological investigations of the surrounding structures helps in identifying the foreign body and also for its removal.

\section{REFERENCES}

1. Auluck A, Behanan AG, Pai KM, Shetty C. Recurrent sinusof the cheek due to a retained foreign body: Report of an unusual case. Br Dent J. 2005; 198:337-39.

2. Yanay O, Vaughan DJ, Diab M, Brownstein D, Brogan TV. Retained wooden foreign body in a child's thigh complicated by severe necrotizing fasciitis: A case report and discussion of imaging modalities for early diagnosis. Pediatr Emerg Care. 2001; 17:354-55.

3. Van Der Wal KG, Boukes RJ. Intraorbital bamboo foreign body in a chronic stage: case report. International Journal of Oral \& Maxillofacial Surgery: Trauma; oral surgery; implantology. 2000 Dec;29(6):428-9.

4. Akuner M, Ajay A, Top H. A case of self-inflicted intraorbital injury: Wooden foreign body introduced into the ethmoidal sinus. Ann Plast Surg. 1998;41:422-24.

5. Robinson PD, Rajayogeswaran V, Orr R. Unlikely foreign bodies in unusual facial sites. $\mathrm{Br} \mathrm{J}$ Oral Maxillofac Surg. 1997; 35:36-39.

6. Cameron M, Phillips B. Snookered facial infection secondary to occult foreign body. Int $\mathrm{J}$ Oral Maxillofac Surg. 2006;35: 373-75.

7. Paoli JR, Dekeister C. Atoothintheorbit. Br. J Oral Maxillofac Surg. 2001;39(4):327.

8. Oikarinen KS, Nieminen TM, Makarauren H, Pyhtinen J. Visibility of foreign bodies in soft tissue in plain radiographs, computed tomography, magnetic resonance imaging and ultrasound. Aninvitrostudy. Int JOralMaxillofacSurg.1993;22: 119-24.

9. Holmes PJ, Miller JR, Gutta R, Louis PJ. Intraoperativeimaging techniques: $A$ guide to retrieval of foreign bodies. Oral Surg Oral Med Oral Pathol Oral Radiol Endod. 2005; 100:614-18.

10. Eggers G, Haag C, Hassfeld S. Imageguidedremovalofforeign bodies. $\mathrm{Br} \quad \mathrm{J}$ Oral Maxillofac Surg. 2005:404-09. 